\title{
OPTIMIZATION OF MICROWAVE- AND ULTRASONIC-ASSISTED EXTRACTION OF MAHKOTA DEWA (PHALERIA MACROCARPA [SCHEFF.] BOERL.) FRUIT PULP
}

\author{
ROSITA HANDAYANI, ANDRE BANGUN, PASKAH DEWI DEBORAH, ABDUL MUN'IM* \\ Department of Pharmacognosy and Phytochemistry, Faculty of Pharmacy, Universitas Indonesia, Depok 16424, Indonesia. \\ Email: munim@farmasi.ui.ac.id
}

Received: 26 September 2019, Revised and Accepted: 17 December 2019

\section{ABSTRACT}

Objective: This work aimed to determine the optimal extraction conditions of Mahkota dewa using different extraction methods: microwave-assisted extraction with ethanol (MAE-ethanol), ultrasonic-assisted extraction using a choline chloride natural deep eutectic solvent (UAE-NADES), and Soxhlet and reflux extractions.

Methods: Experimental design was performed through Box-Behnken. The efficiency of the methods was evaluated based on the total phenolic content (TPC) and antioxidant activity. The presence of relevant compounds was qualitatively assessed by high-performance liquid chromatography (HPLC).

Results: For the MAE-ethanol method, optimum extraction was achieved with $65 \%$ ethanol, in 1 min under $30 \%$ microwave power, and a $1: 12$ samplesolvent ratio, which yielded a TPC and antioxidant activity of $62.79 \pm 0.74 \mathrm{mg}$ gallic acid equivalents (GAE)/g powder and $30.48 \pm 0.32 \%$, respectively. In UAE-NADES, the optimal conditions were choline chloride: lactic acid ratio of $1: 4$ with a 50\% water addition, 20 min extraction (TPC and antioxidant activity of $65.25 \mathrm{mg} \mathrm{GAE} / \mathrm{g}$ powder and $26.45 \pm 0.02 \%$ ). The Soxhlet and reflux methods gave a TPC of $49.68 \pm 0.59$ and $50.98 \pm 0.54 \mathrm{mg}$ GAE/g powder, and antioxidant activity of $22.87 \pm 0.13 \%$ and $25.97 \pm 0.34 \%$, respectively. Qualitative HPLC analysis showed the presence of quercetin, mahkoside A, 4,6-dihydroxy-4-methoxybenzophenone-2-0- $\beta$-D-glucopyranoside, and mangiferin.

Conclusion: MAE-ethanol was more efficient than the conventional Soxhlet and reflux methods and performed similarly to UAE-NADES in terms of TPC.

Keywords: Antioxidant activity, Mahkota dewa, Microwave-assisted extraction, Natural deep eutectic solvents, Phaleria macrocarpa, Total phenolic content. (C) 2020 The Authors. Published by Innovare Academic Sciences Pvt Ltd. This is an open access article under the CC BY license (http://creativecommons. org/licenses/by/4. 0/) DOI: http://dx.doi.org/10.22159/ijap.2020.v12s1.FF002

\section{INTRODUCTION}

Mahkota dewa (Phaleria macrocarpa [Scheff.] Boerl.) is a species of shrub of the Thymelaeaceae family and is indigenous to New Guinea, the second-largest island in the world [1]. This plant has several common names, such as simalakama (Sumatra), makutadewa (Java), makuto rojo or makuto ratu (Central Java), and raja obat (Banten) [2]. In China, it is called Pau, and in Europe, it is known as crown god or god's crown (Quattrocchi, 2012). Its leaves and fruits have been commonly used to treat several conditions, including cancer, cardiovascular diseases, diabetes, hypertension, rheumatic and liver ailments, and to prevent strokes [3]. Recently, Mahkota dewa was proven to inhibit the angiotensin-converting enzyme, which leads to a decrease in blood pressure. The pharmacological activity of Mahkota dewa comes from the phenolic content which acts as an antioxidant agent [4].

Several secondary metabolites have been isolated from Mahkota dewa. The fruit contains icariside C3, mangiferin, 6,4-dihydroxy4-methoxybenzophenone-2-O- $\beta$-D- glucopyranoside (6,4-DHMP), phalerin, and gallic acid [5]. The fruit pericarp has kaempferol, myricetin, and rutin, while the mesocarp and seed contain naringin and quercetin [3]. In previous studies, the extraction of P. macrocarpa was performed with organic solvents, such as petroleum ether and methanol, and water [6]. However, the toxicity, degradation, and low selectivity are known issues when using conventional solvents for extraction processes, which are also usually time consuming. These problems are directly related to environmental pollution, cost efficiency, and the quality and purity of the final product.

To overcome these limitations, some strategies include the reduction of solvent using sustainable technologies, such as microwave- and ultrasonic-assisted extraction (MAE and UAE), supercritical fluid extraction, among others. Replacing the conventional solvents with environmentally-friendly alternatives is another strategy. The use of modern extraction techniques can involve both conventional solvents, for example, ethanol, or eco-friendly/green solvents. Green solvents are non-toxic, effective alternatives to replace organic solvents. An example of green solvents is the natural deep eutectic solvents (NADES), which consist of a mixture of compounds that are ubiquitous in the cells of a great number of organisms, i.e. amino acids, sugars, organic acids, and choline derivatives [7].

In addition to being environmentally-friendly, NADES have interesting properties that may be useful for natural products' chemistry. For example, Cvjetko Bubalo et al. reported that the extraction of total phenolic compounds in grape skins is more effective when using NADES than with conventional organic solvents [8]. Similarly, García et al. used choline chloride NADES to extract total phenols in olive oil and found an increase of $20 \%$ in the extraction compared to methanol and water [9].

The aim of this work is to determine the optimal conditions of the total phenolic compounds extraction of Mahkota dewa fruit pulp using different methods: MAE using ethanol (MAE-ethanol), UAE using a choline chloride NADES (UAE-NADES), Soxhlet extraction, and reflux. The efficiency of the methods was evaluated based on the total phenolic content (TPC) and antioxidant activity.

\section{MATERIALS AND METHODS}

\section{Materials}

Fruit pulp of Mahkota dewa (Phaleria macrocarpa [Scheff.] Boerl.) was acquired from Purworejo, Central Java and was identified by Indonesian Institute of Sciences (LIPI). Mahkoside A, 6,4-DHMP, and mangiferin were obtained from Dr. Aprilita R. and Sigma Aldrich (USA). Quercetin, 
urea, 1,1-diphenyl-2-picrylhydrazyl (DPPH), and gallic, tartaric, and lactic acids were purchased from Sigma-Aldrich (USA). Butylated hydroxytoluene (Bratachem, Indonesia), choline chloride was obtained from Xian Rongsheng Biotechnology (China). Demineralized water and sodium bicarbonate were purchased from Brataco (Indonesia). FolinCiocalteu reagent was from Merck (Germany).

\section{MAE}

Response surface methodology was carried out to determine the optimal extraction conditions. Four independent variables with three levels each were used to design 27 experimental runs based on a BoxBehnken design (Table 1), using the Design Expert ${ }^{\circledR} 10.03$ software.

The fruit was dried and pulverized; then, $1 \mathrm{~g}$ of powder was placed in a $250 \mathrm{~mL}$ flat-bottomed flask. Subsequently, the solvent (ethanol-water mixture, Table 1) was added to the flask. Three different samplesolvent ratios were used, Table 1 . The mixture was then extracted in a modified MAE apparatus (Modena, Italy) at 3 extraction times under three different power settings, as indicated in Table 1 . The resulting mixture was then filtered and the filtrate evaporated in a water bath at $50^{\circ} \mathrm{C}$ until a solid extract was obtained. The yield of extract of each run was calculated using the following equation:

$$
\text { Yield of extract }(\%)=\frac{\text { Weight of extract }}{\text { Weight of sample }} \times 100 \%
$$

TPC was measured as reported by Bobo-Garcia et al. [10]. The antioxidant activity of the extracts was determined using DPPH as described by Musa using butylated hydroxy toluene as standard [11].

\section{Preparation and selection of NADES}

The salt compound (choline chloride) and hydrogen bond donor (HBD) were weighed a determined ratio (Table 2) and mixed. Then, the mixture was stirred and heated for $30-90 \mathrm{~min}$ in a hotplate at $50^{\circ} \mathrm{C}$ for the solid-liquid compound combinations and at $80^{\circ} \mathrm{C}$ for the solid-solid mixture until a clear solution was formed [12].

One gram of the fruit pulp powder was dissolved in $10 \mathrm{~mL}$ of NADES 1 , 2 , and 3 (Table 2) and was extracted using an ultrasonic bath (Krisbow, China) at $37 \mathrm{kHz}$ for $20 \mathrm{~min}$ [8]. The mixture was then filtered and stored in light protected-vials. After measuring the TPC [10], the solvent with the highest phenolic content was selected for further extraction under different conditions (Table 3).

\section{UAE using NADES}

The Design Expert ${ }^{\circledR} 10.03$ software was used to obtain the optimal conditions for total phenolic extraction. The variables were the choline chloride: lactic acid (ChCl: LA) molar ratio, percent addition of water,

Table 1: Extraction parameters

\begin{tabular}{lllll}
\hline \multirow{2}{*}{ No. factors } & \multicolumn{2}{l}{ Level } & \\
\cline { 3 - 5 } & & $\mathbf{- 1}$ & $\mathbf{0}$ & $\mathbf{+ 1}$ \\
\hline 1. & Ethanol concentration (\%) & 50 & 65 & 80 \\
2. & Sample-solvent ratio & $1: 10$ & $1: 12$ & $1: 14$ \\
3. & Extraction time (min) & 1 & 2 & 3 \\
4. & Microwave power (\%) & 30 & 50 & 70 \\
\hline
\end{tabular}

Table 2: Composition of the NADES

\begin{tabular}{lllll}
\hline Component & Molar ratio & $\begin{array}{l}\text { Solvent } \\
\text { code }\end{array}$ & Reference \\
\cline { 1 - 3 } Salt & HBD & NADES-1 & {$[13]$} \\
\hline Choline chloride & $\begin{array}{l}\text { Lactic } \\
\text { acid }\end{array}$ & $1: 2$ & NADES-2 & {$[14]$} \\
Choline chloride & $\begin{array}{l}\text { Tartaric } \\
\text { acid }\end{array}$ & $1: 1$ & NADES-3 & {$[15]$} \\
Choline chloride & Urea & $1: 2$ &
\end{tabular}

HBD: Hydrogen bond donor, NADES: Natural deep eutectic solvents and extraction time (Table 3). From the variables considered, an extraction design of 15 runs was obtained.

One gram of the fruit pulp powder was dissolved in $10 \mathrm{~mL}$ of the selected NADES. Extraction was performed using an ultrasonic apparatus for 20-60 min then centrifuging for $20 \mathrm{~min}$ at $4500 \mathrm{rpm}$. The samples were filtered to obtain a liquid extract which was diluted with demineralized water until the limit of measuring flask was reached. The TPC and antioxidant activity were determined as mentioned in the MAE process [10]. Antioxidant activity of the extracts was determined using DPPH reagent as described in Musa. Butylated hydroxytoluene was used as standards for comparing the antioxidant potential [11].

\section{Soxhlet extraction}

Dried and pulverized fruit pulp $(20 \mathrm{~g})$ were extracted in $70 \%$ ethanol for $6 \mathrm{~h}$ using a Soxhlet apparatus. The resulting mixture was allowed to cool overnight to yield the optimum content of phenolic compounds. The extract was dried with a rotary vacuum evaporator and then in a vacuum oven at $40^{\circ} \mathrm{C}$. The TPC and antioxidant activity were measured as mentioned in the previous section.

\section{Reflux extraction}

Similar to the Soxhlet extraction, $20 \mathrm{~g}$ of sample were extracted in $200 \mathrm{~mL}$ of $70 \%$ ethanol for $2 \mathrm{~h}$ at $80^{\circ} \mathrm{C}$ using a reflux apparatus [16]. The resulting mixture was evaporated under vacuum at $50^{\circ} \mathrm{C}$, and subsequently dried at $40^{\circ} \mathrm{C}$ in a vacuum oven to obtain the crude extract. TPC and antioxidant activity were measured as described in the previous sections.

\section{High-performance liquid chromatography (HPLC) analysis}

HPLC (Shimadzu LC 20AT, Japan) was performed with a C-18 column (4.6 $\mathrm{mm} \times 250 \mathrm{~mm}$, YMC Triart, Japan) and a UV-Vis diode array under the following conditions [16]. Acetonitrile: distilled water: acetic acid (89:10:1) as mobile phase with a $1 \mathrm{~mL} / \mathrm{min}$ flow rate and a $20 \mu \mathrm{L}$ injection volume. The detection wavelength was $254 \mathrm{~nm}$ for quercetin, $280 \mathrm{~nm}$ for mahkoside A, and $288 \mathrm{~nm}$ for 6,4-DHMP and mangiferin.

\section{Determination of optimal conditions based on TPC}

The TPC from each run of each method was input into the Design Expert ${ }^{\circledR}$ software to establish a mathematical model and optimize the MAE and UAE processes. The optimal conditions were determined from multiple non-linear regressions plotted as a three-dimensional response surface graph.

\section{Correlation between TPC and antioxidant activity}

Pearson's correlation was employed to identify a possible association between TPC (X variable) and DPPH free radicals scavenging, which corresponds to the antioxidant activity ( $\mathrm{Y}$ variable). This was carried out with a $5 \%$ significance level.

\section{RESULTS AND DISCUSSION}

Table 4 shows the results for yield, TPC and DPPH scavenging activity for the MAE method under different conditions. The highest yield, $37.3 \%$, was for run 18 , and the lowest, $11.1 \%$, for run 19 . Overall, using $50 \%$ ethanol provided higher yields than any other concentration. This is possibly caused by the high dielectric constant of water and the dissipation factor of ethanol, thus the 1:1 mixture of ethanol-water ( $50 \%$ ethanol) is capable to absorb more of the microwave irradiation and increase the heat efficiency.

Table 3: UAE-NADES variables

\begin{tabular}{lllll}
\hline \multirow{2}{*}{ No. } & Variable & Level \\
\cline { 3 - 5 } & & $\mathbf{- 1}$ & $\mathbf{0}$ & $\mathbf{+ 1}$ \\
\hline 1. & Choline chloride: Lactic acid molar ratio & $1: 2$ & $1: 3$ & $1: 4$ \\
2. & Percent addition of water (\%) & 30 & 50 & 70 \\
3. & Extraction time (min) & 20 & 40 & 60 \\
\hline \multicolumn{2}{l}{ NADES: Natural deep eutectic solvents, UAE: Ultrasonic-assisted extraction }
\end{tabular}


Table 4: Box-Behnken design for MAE

\begin{tabular}{llllllll}
\hline Run & $\begin{array}{l}\text { Ethanol } \\
\text { concentration (\%) }\end{array}$ & $\begin{array}{l}\text { Sample-solvent } \\
\text { ratio }\end{array}$ & $\begin{array}{l}\text { Extraction } \\
\text { time (min) }\end{array}$ & $\begin{array}{l}\text { Power of } \\
\text { instrument }(\%)\end{array}$ & $\begin{array}{l}\text { \% } \\
\text { yield }\end{array}$ & $\begin{array}{l}\text { Total phenolic content } \\
\text { (mg gallic acid } \\
\text { equivalents/g powder) }\end{array}$ & $\begin{array}{l}\text { DPPH scavenging/ } \\
\text { antioxidant activity (\%), } \\
\text { c=100 } \boldsymbol{\mu g} / \mathbf{m L})\end{array}$ \\
\hline 1 & 80 & $1: 10$ & 2 & 50 & 15.1 & $24.38 \pm 0.33$ & $27.05 \pm 0.28$ \\
2 & 50 & $1: 12$ & 2 & 30 & 19.4 & $29.96 \pm 0.09$ & $24.27 \pm 0.19$ \\
3 & 65 & $1: 12$ & 3 & 30 & 22.7 & $37.75 \pm 0.79$ & $23.29 \pm 0.25$ \\
4 & 50 & $1: 12$ & 2 & 70 & 18 & $29.36 \pm 0.12$ & $26.60 \pm 0.20$ \\
5 & 65 & $1: 10$ & 1 & 50 & 18.5 & $29.84 \pm 0.38$ & $24.18 \pm 0.09$ \\
6 & 65 & $1: 12$ & 3 & 70 & 18.7 & $31.58 \pm 0.41$ & $23.93 \pm 0.47$ \\
7 & 80 & $1: 12$ & 1 & 50 & 18.9 & $34.79 \pm 0.22$ & $22.69 \pm 0.06$ \\
8 & 65 & $1: 10$ & 2 & 30 & 17.9 & $29.58 \pm 0.13$ & $24.87 \pm 0.10$ \\
9 & 80 & $1: 12$ & 2 & 70 & 12.5 & $22.06 \pm 0.20$ & $27.86 \pm 0.04$ \\
10 & 80 & $1: 14$ & 2 & 50 & 23.4 & $37.24 \pm 0.75$ & $25.58 \pm 0.22$ \\
11 & 65 & $1: 12$ & 2 & 50 & 31.9 & $49.64 \pm 0.05$ & $22.12 \pm 0.20$ \\
12 & 65 & $1: 12$ & 1 & 70 & 32.7 & $43.26 \pm 0.10$ & $25.25 \pm 0.04$ \\
13 & 65 & $1: 14$ & 2 & 70 & 25.2 & $37.14 \pm 0.04$ & $30.48 \pm 0.26$ \\
14 & 80 & $1: 12$ & 3 & 50 & 30.9 & $51.93 \pm 0.50$ & $19.42 \pm 0.09$ \\
15 & 65 & $1: 12$ & 1 & 30 & 36.4 & $62.79 \pm 0.74$ & $17.51 \pm 0.14$ \\
16 & 80 & $1: 12$ & 2 & 30 & 29.1 & $41.71 \pm 0.72$ & $25.99 \pm 0.19$ \\
17 & 50 & $1: 14$ & 2 & 50 & 16.5 & $20.22 \pm 0.20$ & $17.84 \pm 0.35$ \\
18 & 50 & $1: 12$ & 3 & 50 & 37.3 & $58.43 \pm 0.18$ & $26.69 \pm 0.22$ \\
19 & 65 & $1: 10$ & 2 & 70 & 11.1 & $13.41 \pm 0.29$ & $21.21 \pm 0.13$ \\
20 & 65 & $1: 14$ & 2 & 30 & 12.7 & $17.97 \pm 0.12$ & $29.49 \pm 0.22$ \\
21 & 65 & $1: 14$ & 1 & 50 & 26 & $41.46 \pm 0.31$ & $17.36 \pm 0.18$ \\
22 & 65 & $1: 14$ & 3 & 50 & 30.9 & $38.55 \pm 0.41$ & $20.65 \pm 0.22$ \\
23 & 65 & $1: 10$ & 3 & 50 & 32.6 & $49.73 \pm 0.39$ & \\
24 & 50 & $1: 12$ & 1 & 50 & 16.7 & $18.65 \pm 0.13$ & \\
25 & 50 & $1: 10$ & 2 & 50 & 26.9 & $39.97 \pm 0.15$ & \\
\hline
\end{tabular}

MAE: Microwave-assisted extraction, DPPH: 1,1-diphenyl-2-picrylhydrazyl

A sample-solvent ratio of 1:12 had the best yields compared to any other ratio. In general, when more solvent is used for an extraction process, more crude extract will be obtained. However, the 1:14 ratio probably led to a decrease in the absorption of microwave radiation because of the excess solvent. Therefore, the extraction process would require more microwave power [13]. A combination of the longest extraction time (3 $\mathrm{min})$ and intermediate microwave power $(50 \%)$ resulted in the highest yields. This was likely due to an increase in extraction efficiency, which has a linear relation with the extraction time [17]

The determination of TPC is based on the reducing capacity of a sample using gallic acid as standard. The calibration curve using gallic acid yielded the linear equation $y=0.0066 x+0.1041, r=0.9993$. This equation and the absorbance of each sample were used to determine the TPC. From Table 4, it can be seen that the highest TPC was for run 15, which is probably due to the polarity of the solvent (ethanol 65\%). A previous study showed that the presence of a small amount of water helps the solvent to diffuse into cell matrices, improves the thermal conductivity, and eases the mass transfer of compounds in the solvent. This was also confirmed by Song et al. [18], who extracted the leaves of Ipomoea batatas and observed that a $60-80 \%$ ethanol-water mixture would yield optimal results for the extraction of phenolic compounds.

It is worth noting that a high extraction yield is not equivalent to high phenolic content. Most likely, the degradation of thermolabile constituents of the sample, such as phenolic compounds, would be prevented if the extraction time is short. On the contrary, a longer period of microwave radiation, which would result in a higher extraction yield, increases degradation. As seen in Table 4, the highest TPC was obtained for $1 \mathrm{~min}$ of irradiation, while the highest yield was achieved for a 3 min extraction.

Different from the MAE, which used a mixture of ethanol and water as solvent, the UAE method was carried out using a NADES. As mentioned above, three NADES were prepared with a combination of choline chloride and either lactic acid, tartaric acid, or urea (Table 2, NADES-1, 2 , and 3). From these combinations, the best solvent was selected according to the TPC results (Fig. 1). The solvent with lactic acid as HBD, NADES- 1 , yielded the best results: TPC $=42.38 \pm 0.01 \mathrm{mg}$ gallic acid equivalents (GAE)/g of powder. This is likely because, compared to tartaric acid and urea, lactic acid is a liquid with low viscosity. High viscosity in NADES can affect the extraction of phenolic components because it can reduce the solubility of compounds [19]. NADES containing tartaric acid have a higher viscosity than those with lactic acid, resulting in a decreased mass transferability and thus a lower TPC [15]. In addition to the viscosity, the polarity of NADES influences its ability to extract phenolic compounds [20]. NADES containing urea can damage the structure of plant cells, increasing the extraction yield, but cannot extract phenolic compounds with a different polarity [14].

NADES-1 was thus selected as solvent in further extraction processes to obtain the optimal conditions. It has been reported that the addition of water reduces the viscosity of NADES and, as mentioned above, this would increase the TPC [21]. Table 5 shows the results of $15 \mathrm{UAE}$ experiments; the highest TPC, $65.25 \pm 0.01 \mathrm{mg}$ GAE/g powder, was achieved in run 6 (1:4 ChCl: LA molar ratio, 50\% water, extraction time $20 \mathrm{~min}$ ). In contrast, the lowest TPC, $32.55 \pm 0.01 \mathrm{mg}$ GAE/g powder, was for run 11 (1:2 ChCl: LA, 30\% water, $40 \mathrm{~min}$ ). The viscosity of the solvent may be the most important parameter affecting the TPC. However, it is likely that an excessive water addition will cause the concentration of phenols in the mixture to decrease so that the TPC would also decrease.

In various studies, TPC is positively correlated with the antioxidant activity of a sample [22]. In this study, we did not observe a direct correlation between these two parameters because the total volume from each extraction is different (Table 6). The runs were therefore classified according to their volume and analyzed using Pearson's correlation, $\mathrm{p}<0.05$ and $\mathrm{r}=0.948$ were obtained, indicating that TPC is indeed positively correlated with the antioxidant activity.

The effect of different extraction variables was analyzed. An ANOVA analysis can demonstrate the significance between two factors on one response. The results indicate that the $\mathrm{ChCl}$ : LA ratio, water percentage, and extraction time had a significant effect with $\mathrm{p}<0.05$. Furthermore, none of the 15 runs had an antioxidant activity of more than $50 \%$. Run 6, which had the highest TPC, showed antioxidant activity of $26.45 \pm 0.02 \%$. 
The overall results demonstrate that the MAE-ethanol and UAE-NADES methods at the optimal conditions produced a higher TPC and antioxidant activity compared to conventional Soxhlet and reflux methods (Fig. 2). Although UAE-NADES showed the highest TPC, the difference with the MAE-ethanol method is not significant. Contrastingly, the latter yielded higher antioxidant activity than
UAE-NADES, and the difference here was statistically significant. Thus, it can be concluded that the best extraction of Mahkota dewa (Phaleria macrocarpa) fruits pulp powder was achieved using the MAE-ethanol method at $65 \%$ of ethanol with a sample: solvent ratio of $1: 12$, with an extraction time of $1 \mathrm{~min}$ and microwave power of $30 \%$.

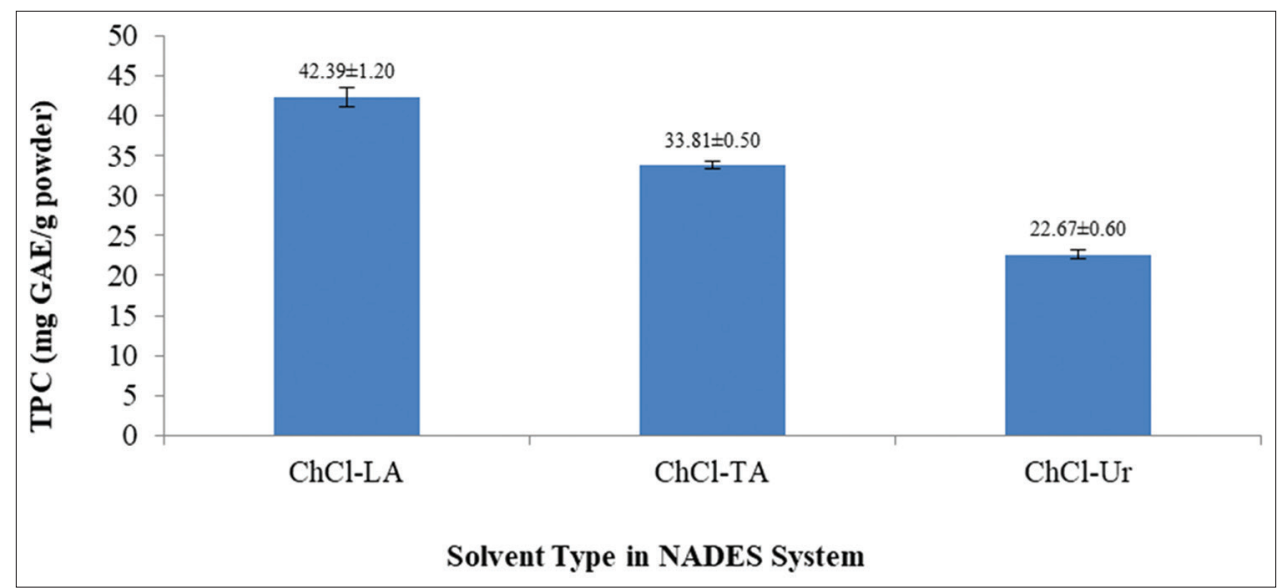

Fig. 1: Total phenolic content of Mahkota dewa pulp powder using natural deep eutectic solvents. Cholin chloride: lactic acid 1:2 (ChClLA); cholin chloride: tartaric acid 1:1 (ChCl-TA); cholin chloride: urea 1:2 (ChCl-Ur)

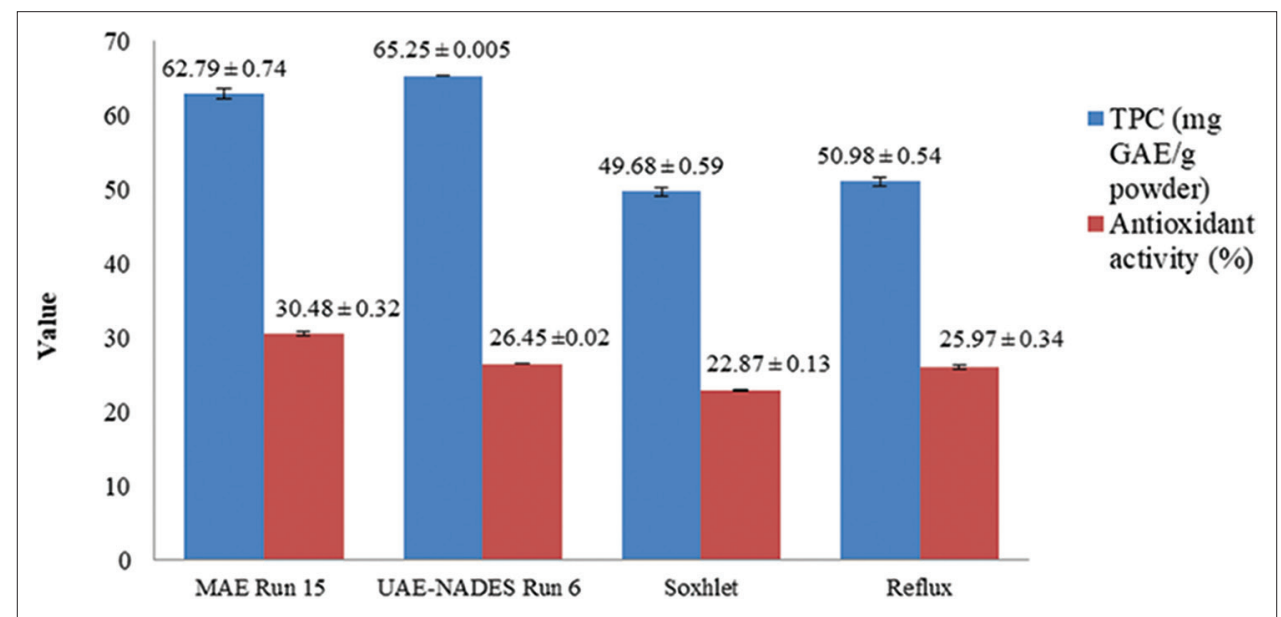

Fig. 2: Comparison of the total phenolic content and antioxidant activity of the Mahkota dewa samples obtained using different extraction methods

Table 5: TPC and DPPH scavenging (antioxidant activity) using the UAE-NADES method

\begin{tabular}{llllll}
\hline Run & Ratio ChCl:LA (g/mL) & Water addition (\%) & Extraction time (min) & $\begin{array}{l}\text { TPC (mg gallic acid } \\
\text { equivalents/g powder) }\end{array}$ & $\begin{array}{l}\text { DPPH scavenging/antioxidant } \\
\text { activity (\%) }\end{array}$ \\
\hline 1 & $1: 3$ & & & 34.58 & $25.66 \pm 0.38$ \\
2 & $1: 4$ & 30 & 20 & 54.01 & $22.37 \pm 0.44$ \\
3 & $1: 3$ & 50 & 60 & 45.26 & $12.15 \pm 0.27$ \\
4 & $1: 2$ & 70 & 40 & 52.10 & $18.80 \pm 0.02$ \\
5 & $1: 2$ & 70 & 20 & 44.62 & $29.06 \pm 0.01$ \\
6 & $1: 4$ & 50 & 60 & 65.25 & $26.45 \pm 0.02$ \\
7 & $1: 3$ & 50 & 40 & 44.00 & $24.84 \pm 0.02$ \\
8 & $1: 3$ & 30 & 40 & 62.30 & $26.16 \pm 0.01$ \\
9 & $1: 3$ & 50 & 40 & 62.00 & $21.82 \pm 0.01$ \\
10 & $1: 4$ & 50 & 40 & 62.17 & $41.33 \pm 0.02$ \\
11 & $1: 2$ & 70 & 60 & 32.55 & $22.62 \pm 0.01$ \\
13 & $1: 3$ & 30 & 40 & 63.58 & $25.23 \pm 0.02$ \\
14 & $1: 4$ & 70 & 40 & 63.06 & $30.43 \pm 0.02$ \\
15 & $1: 2$ & 50 & 60 & 52.72 & $35.67 \pm 0.02$ \\
\hline
\end{tabular}

DPPH: 1,1-diphenyl-2-picrylhydrazyl, TPC: Total phenolic content, NADES: Natural deep eutectic solvents, UAE: Ultrasonic assisted extraction, ChCl:LA: Choline chloride:lactic acid 


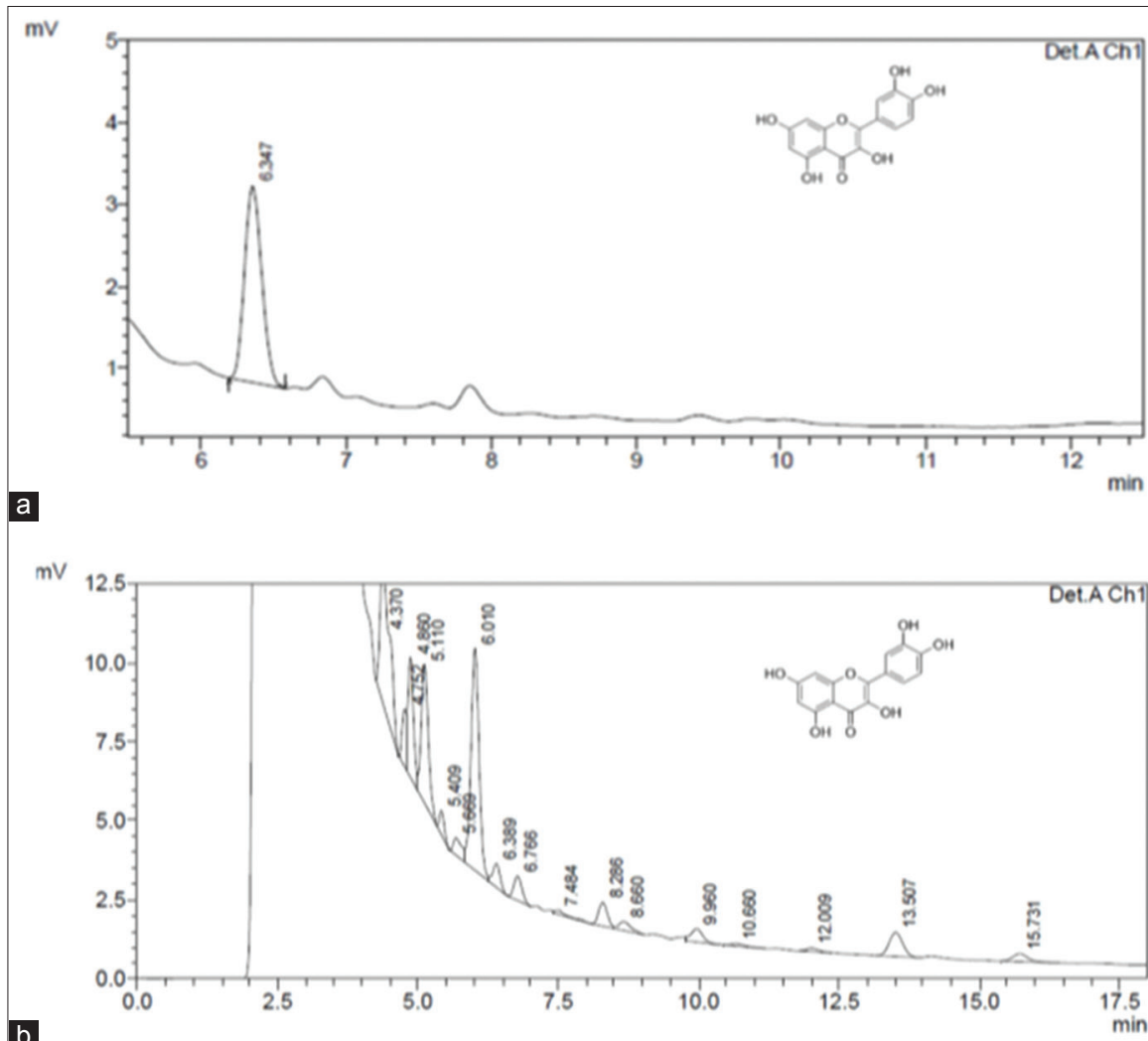

mV

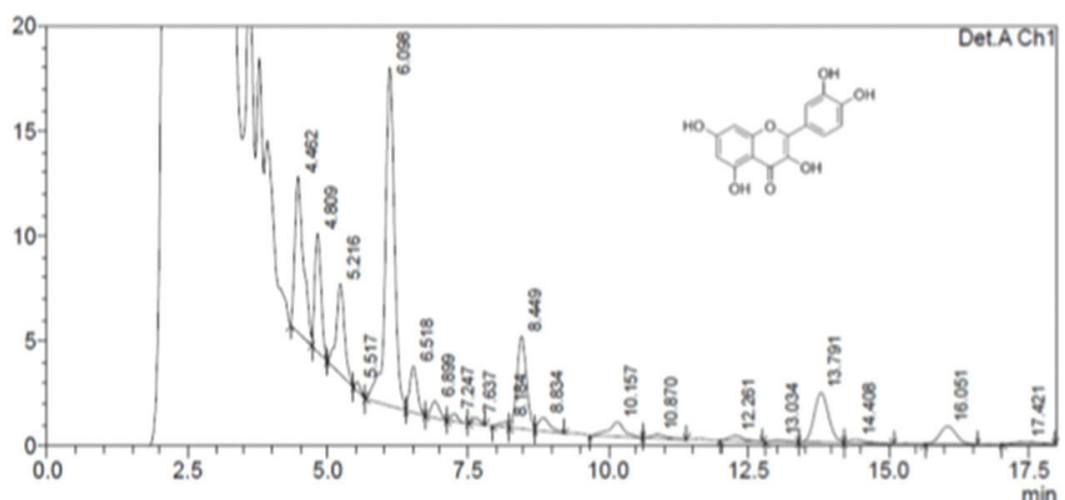

C

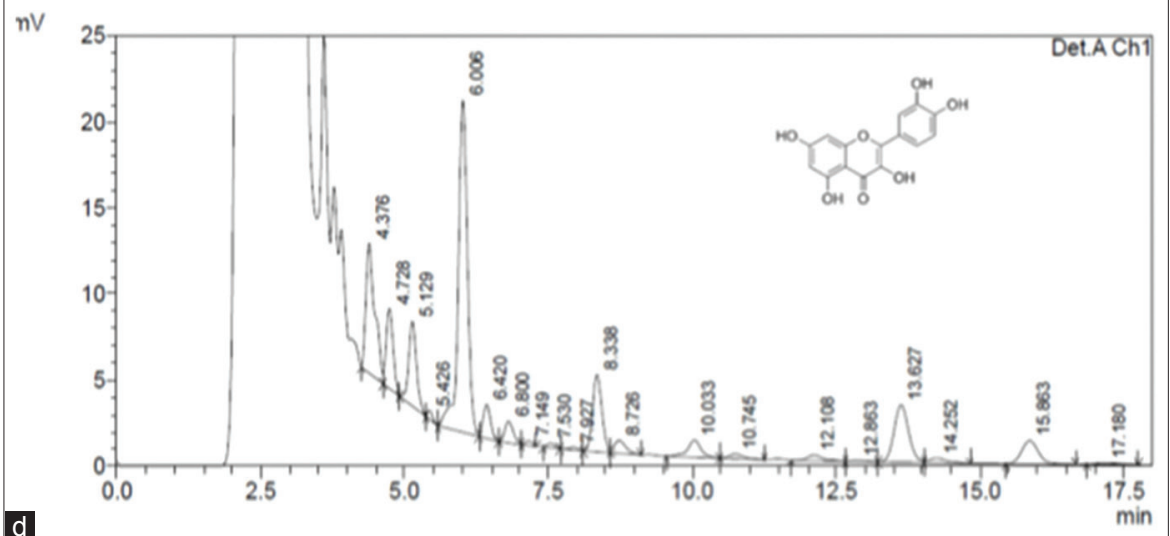

Fig. 3: Chromatograms of quercetin standard (a) and Mahkota dewa fruit pulp extracts obtained from three different methods: Microwave-assisted extraction (b), Soxhlet (c), reflux (d)

Previous studies show that the fruit pulp of Mahkota dewa contains a number of secondary metabolites, such as mahkoside A [23], quercetin, mangiferin, and several benzophenone derivatives [24]. In this study, a qualitative HPLC analysis was performed to identify the presence of quercetin, mahkoside A, mangiferin, and 6,4-DHMP in the fruit pulp extract. 
Table 6: Classification of UAE-NADES experiments from Table 5 according to the extraction volume

\begin{tabular}{ll}
\hline Volume (mL) & Run \\
\hline 5 & 11 \\
10 & $1,5,7,14,15$ \\
20 & $2,4,6,8,9,13$ \\
25 & 12 \\
50 & 3,10 \\
\hline
\end{tabular}

NADES: Natural deep eutectic solvents, UAE: Ultrasonic-assisted extraction

Quercetin (retention time $6.38 \mathrm{~min}$ ) was found in all the extracts obtained from the MAE, Soxhlet, and reflux methods (Fig. 3). Magniferin, mahkoside A, and 6,4-DHMP, which are benzophenone derivatives, were analyzed at $280 \mathrm{~nm}$ [16]. The chromatograms for these compounds show peaks at 8.134 and 11.286 min (mahkoside A), 6.173, 8.171, and $11.338 \mathrm{~min}$ (6,4-DHMP), and 8.034, 9.806, 10.714, and $11.168 \mathrm{~min}$ (mangiferin). The extracts obtained from the MAE, Soxhlet, and reflux methods showed four peaks, three of which correspond to the three standards.

\section{CONCLUSION}

The optimal conditions for the phenolic extraction of $P$. macrocarpa fruit pulp were obtained using the MAE method for a 1 min extraction under 30\% microwave power, using 65\% ethanol, and a sample-solvent ratio of 1:12 (w/v). This method was more efficient than conventional Soxhlet and reflux methods. Comparing the TPC, its efficiency was similar to that of UAE-NADES, but its antioxidant activity was better.

\section{ACKNOWLEDGMENTS}

This study was supported by DRPM Universitas Indonesia through Hibah PITTA 2018. The authors would like to thank Dr. Aprilitia Rinayanti from Esa Unggul University, Indonesia, for providing Mahkoside A, 6,4-DHMP, and mangiferin.

\section{CONFLICTS OF INTEREST}

The authors declare that they have no conflicts of interest.

\section{REFERENCES}

1. Kurnia D, Akiyama K, Hayashi H. 29-Norcucurbitacin derivatives isolated from the Indonesian medicinal plant, Phaleria macrocarpa (Scheff.) Boerl. Biosci Biotechnol Biochem 2008;72:618-20.

2. Easmin MS, Sarker MZ, Ferdosh S, Shamsudin SH, Yunus KB, Uddin MS et al. Bioactive compounds and advanced processing technology: Phaleria macrocarpa (Sheff.) Boerl, a review. J Chem Technol Biotechnol 2015;90:981-91.

3. Hendra R, Ahmad S, Sukari A, Shukor MY, Oskoueian E. Flavonoid analyses and antimicrobial activity of various parts of Phaleria macrocarpa (Scheff.) Boerl fruit. Int J Mol Sci 2011;12:3422-31.

4. Rinayanti A, Radji M, Mun'im A, Suyatna FD. Screening angiotensin converting enzyme (ACE) inhibitor activity of antihypertensive medicinal plants from Indonesia. Int J Pharm Teach Pract 2013;4:527-32.

5. Oshimi S, Zaima K, Matsuno Y, Hirasawa Y, Iizuka T, Studiawan H, et al. Studies on the constituents from the fruits of Phaleria macrocarpa. J Nat Med 2008;62:207-10.
6. Ali RB, Atangwho IJ, Kuar N, Ahmad M, Mahmud R, Asmawi MZ. In vitro and in vivo effects of standardized extract and fractions of Phaleria macrocarpa fruits pericarp on lead carbohydrate digesting enzymes. BMC Complement Altern Med 2013;13:39.

7. Espino M, de los Ángeles Fernández M, Gomez FJ, Silva MF. Natural designer solvents for greening analytical chemistry. TrAC Trends Anal Chem 2016;76:126-36

8. Cvjetko Bubalo M, Ćurko N, Tomašević M, Kovačević Ganić K, Radojčić Redovniković I. Green extraction of grape skin phenolics by using deep eutectic solvents. Food Chem 2016;200:159-66.

9. García A, Rodríguez-Juan E, Rodríguez-Gutiérrez G, Rios JJ, FernándezBolaños J. Extraction of phenolic compounds from virgin olive oil by deep eutectic solvents (DESs). Food Chem 2016;197:554-61.

10. Bobo-García G, Davidov-Pardo G, Arroqui C, Vírseda P, MarínArroyo MR, Navarro M. Intra-laboratory validation of microplate methods for total phenolic content and antioxidant activity on polyphenolic extracts, and comparison with conventional spectrophotometric methods. J Sci Food Agric 2015;95:204-9.

11. Musa KH, Abdullah A, Kuswandi B, Hidayat MA. A novel high throughput method based on the DPPH dry reagent array for determination of antioxidant activity. Food Chem 2013;141:4102-6.

12. Dai Y, Witkamp GJ, Verpoorte R, Choi YH. Natural deep eutectic solvents as a new extraction media for phenolic metabolites in Carthamus tinctorius L. Anal Chem 2013;85:6272-8.

13. Wei Z, Qi X, Li T, Luo M, Wang W, Zu Y, et al. Application of natural deep eutectic solvents for extraction and determination of phenolics in Cajanus cajan leaves by ultra performance liquid chromatography. Sep Purif Technol 2015;149:237-44.

14. Paiva A, Craveiro R, Aroso I, Martins M, Reis RL, Duarte AR. ChemInform abstract: Natural deep eutectic solvents-solvents for the $21^{\text {st }}$ century. ChemInform 2014;2:1063-71.

15. Alañón ME, Ivanović M, Gómez-Caravaca AM, Arráez-Román D, Segura-Carretero A. Choline chloride derivative-based deep eutectic liquids as novel green alternative solvents for extraction of phenolic compounds from olive leaf. Arab J Chem 2018;149:237-44.

16. Kim WJ, Veriansyah B, Lee YW, Kim J, Kim JD. Extraction of mangiferin from mahkota dewa (Phaleria macrocarpa) using subcritical water. J Ind Eng Chem 2010;16:425-30.

17. Chan $\mathrm{CH}$, Yusoff R, Ngoh GC, Kung FW. Microwave-assisted extractions of active ingredients from plants. J Chromatogr A 2011;1218:6213-25.

18. Song J, Li D, Liu C, Zhang Y. Optimized microwave-assisted extraction of total phenolics (TP) from Ipomoea batatas leaves and its antioxidant activity. Innov Food Sci Emerg Technol 2011;12:282-7.

19. Chanioti S, Siamandoura P, Tzia C. Application of Natural Deep Eutectic Solvents for Extraction of Polyphenolics from Olive Oil Byproducts Using Microwaves. Waltham: Thermo; 2016. p. 107-9.

20. Huang Y, Feng F, Jiang J, Qiao Y, Wu T, Voglmeir J, et al. Green and efficient extraction of rutin from tartary buckwheat hull by using natural deep eutectic solvents. Food Chem 2017;221:1400-5.

21. Ruesgas-Ramón M, Figueroa-Espinoza MC, Durand E. Application of deep eutectic solvents (DES) for phenolic compounds extraction: Overview, challenges, and opportunities. J Agric Food Chem 2017;65:3591-601.

22. Derakhshan Z, Ferrante M, Tadi M, Ansari F, Heydari A, Hosseini MS, et al. Antioxidant activity and total phenolic content of ethanolic extract of pomegranate peels, juice and seeds. Food Chem Toxicol 2018;114:108-11.

23. Zhang YB, Xu XJ, Liu HM. Chemical constituents from mahkota dewa. J Asian Nat Prod Res 2006;8:119-23.

24. Altaf R, Asmawi MZ, Dewa A, Sadikun A, Umar MI. Phytochemistry and medicinal properties of Phaleria macrocarpa (Scheff.) Boerl. extracts. Pharmacogn Rev 2013;7:73-80. 